\title{
AC 2011-1366: COMBINING HANDS-ON DESIGN, ENGINEERING ANAL- YSIS, AND COMPUTER PROGRAMMING IN A FRESHMAN CIVIL AND ENVIRONMENTAL ENGINEERING COURSE
}

\section{James D. Bowen, University of North Carolina, Charlotte}

Associate Professor, Department of Civil and Environmental Engineering

Peter Thomas Tkacik, University of North Carolina, Charlotte

Peter Tkacik is an Assistant Professor of Mechanical Engineering within the Motorsports focus area. His largest area of research is in the engagement of High School Students and early career Engineering College Students through Hands-On learning activities and exciting visual and experiential research programs.

Other research activities are related to the details of the visual and experiential programs and relate to race car aerodynamics, vehicle dynamics, color-Schlieren shock and compressible flow imaging, and flows around multiple bodies in tandem.

Kimberly Warren, University of North Carolina, Charlotte 


\title{
Combining Hands-On Design, Engineering Analysis, and Computer Programming in a Freshman Civil and Environmental Engineering Course
}

\begin{abstract}
As part of an ongoing project supported by the NSF to increase student retention in the College of Engineering, we are implementing course curriculum enhancements into our second semester freshman Introduction to Civil and Environmental Engineering course. The larger project seeks to improve retention of first and second-year College of Engineering students through development of new opportunities for high school students and College of Engineering freshman, as well as course enhancements to the existing freshman engineering curriculum.

This paper describes efforts to further develop the discipline-specific Introduction to Engineering course taught within the Department of Civil and Environmental Engineering. In particular, we are interested in creating a new environmental-themed culminating group design project for the course that retains the desirable features of the existing structural design and computer simulation project. The focus of this paper is to assess how well our current project is meeting our objectives, and to what extent the desirable features of the current project can be retained in a new project. The paper describes the existing project, summarizes its desirable features, and statistically analyzes some characteristics of the student designs so far. Statistical analysis of past student designs demonstrate the effectiveness of the current project.

Assessment of learning objective achievement by students shows, however, that the course overall fails to meet objectives with respect to computer programming instruction. The new culminating hands-on design experience will involve design and testing of a flocculation and sedimentation basin. It was found that some but not all of the desirable characteristics of the existing project can be mimicked in the new sedimentation design project. Together the existing and new course sections are intended to engage freshman Civil and Environmental students in a hands-on design experience that introduces fundamental engineering analysis concepts while providing instruction on computer programming based analysis tools, and provides content engaging to all Civil and Environmental Engineering majors.
\end{abstract}

\section{Introduction}

Within the College of Engineering at the University of North Carolina at Charlotte are three engineering departments (Civil and Environmental, Mechanical Engineering and Engineering Science, Electrical and Computer) and an Engineering Technology Department. There are two freshman engineering courses, a common first semester course (ENGR 1201), and a department-specific second semester course (ENGR 1202). The first semester common course serves as an introduction to the engineering profession and training in some of the skills needed for professional success ${ }^{1}$. The content of the second semester course, even though it has retained the common course name, has been tailored by the departments to serve different needs. In the Department of Civil and Environmental Engineering Department, we have offered since 
2002 an ENGR 1202 course that applies engineering analysis and computer programming to a group design project. Since 2002 that design project has asked students to design and build a balsa wood bridge. As part of this course, students were originally taught $\mathrm{Matlab}^{2}$ in a way that integrated computer programming instruction into the design project ${ }^{3}$. One notable feature of this course was the automated Matlab-based grading system that provided instant feedback to students on their programming assigments ${ }^{4}$. Since 2002 only the programming portion of the course has changed. In an effort to improve our students' spreadsheet competency, and to provide a better link to subsequent course work, we have since 2008 taught Visual Basic for Applications (VBA) as part of the programming portion of the course rather than Matlab.

As part of an integrated project supported by the NSF to increase student retention in the College of Engineering, we are implementing course curriculum enhancements into our second semester Introduction to Civil and Environmental Engineering course. This curriculum development is done to rectify a perceived weakness in the existing course that it serves less well students interested in Environmental Engineering. We are also working as part of this project to reintroduce the automated grading capability for our VBA-based computer programming portion of the course. The larger project seeks to improve retention of first and second year Engineering students throughout the College through implementation of these five new initiatives:

1. A high school recruitment program aimed at increasing the number of qualified applicants to the College of Engineering,

2. A five-day Summer Engineering Fellowship Camp providing interactive learning activities and field trips to highly qualified juniors and senior high school students,

3. The expansion and enhancement of an undergraduate student mentor program that provides formally trained student coaches to freshman and sophomore engineers,

4. Further development of the first-semester Engineering seminar experience to provide additional exposure to engineering applications and additional targeting of engineering freshman learning communities, and

5. Course curriculum enhancements in each of the discipline-specific Introduction to Engineering courses taught in the second semester of the freshman year.

In Civil and Environmental Engineering, as part of our implementation of initiative 5 above, we will begin to offer an environmental-themed culminating project that hopefully retains the desirable features of the existing design project but broadens the overall course content.

The development of this new design project provides an opportunity for reflection on the similarities and differences between our freshman engineering course and other freshman programs offered elsewhere. It also provides an opportunity for assessment of our experience with the existing course. Our course has many of the features of other freshman programs. First the course follows a first-semester course that is common to all engineering majors ${ }^{5,6}$. The course, the first discipline-specific course within the curriculum, uses in its course design the concept of attached learning ${ }^{7}$ where course content (e.g. computer programming, engineering analysis) is tied to hands-on practical design opportunities. Within the framework for evaluating freshman design courses presented by Sheppard and Jenison ${ }^{8,9}$, our course, while primarily in the individual-content quadrant, uses the culminating design project to provide team-process elements to the course. In addition our course, like others described in the literature, uses active 
and cooperative learning with the intent of improving retention within engineering ${ }^{10}$ and fostering the many non-quantitative skills needed by an engineer for good design ${ }^{11}$.

In this paper we describe the existing course and its culminating design project. Having now used the design project for 14 semesters since 2002 we are able reflect on the desirable characteristics of the current project that we would like to maintain in a new project. An assessment of the design entries so far is used to determine the extent to which these desirable characteristics are actually manifested in the current project. Finally we discuss the strategy in designing the new project to retain as much as possible the desirable characteristics of our existing project.

\section{The Current Course and the Design Project}

The current course combines engineering analysis components (dimensional consistency, static equilibrium), computer programming instruction (VBA), and a group-based structural design project. In this paper we will focus our analysis and assessment on the project portion of the class. In the project, groups of one to three students "compete" against one another to produce the most "profitable" truss-style balsa wood bridge. Bridge profit is calculated as the difference between bridge benefits and costs. An example calculation, using the cost parameters from the Spring 2010 course, is provided in Figure 1. Bridge costs are calculated by summing a

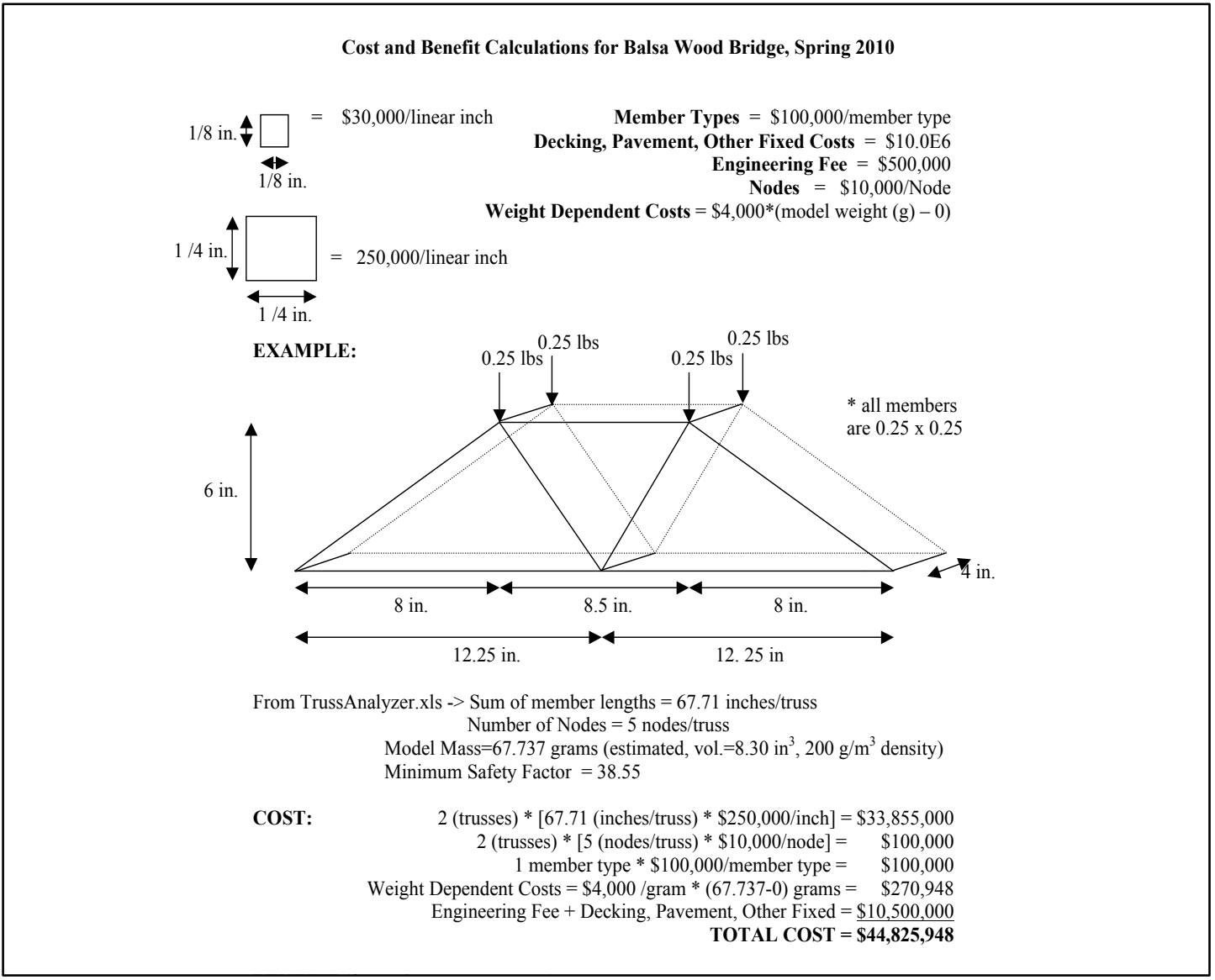

Figure 1. Example Cost Calculation for the Balsa Wood Bridge Design Project, Spring 2010 Semester 
fixed cost, a material cost for the wood used, a construction cost based on the number of bridge nodes and member cross-section sizes, and a foundation cost based on the mass of the bridge. The bridge benefit is determined using a four-parameter "S-shaped" function of bridge strength. Grades are assigned using a weighted comparison of bridge profits (82\%) and the group's accuracy in predicting the strength of their bridge (18\%) according to profit and accuracy grade standards established at the beginning of the semester. Thus, although it is considered a competition, students do not compete for grades, as there is a fixed and predetermined standard that determines each project's grade.

The current group design project is intended to provide a range of learning experiences for the freshman engineers. First being a group project it is intended to introduce freshman engineers to collaborative design and division of labor within a project. Second, it gives students an opportunity to apply engineering analysis and computer simulation to the design of a structure emblematic of Civil Engineers. The project includes destructive testing of preliminary designs, which acquaints students with the uncertainties involved in engineering design, the need to incorporating uncertainty in the design process, and the importance of good construction as a means to achieve design objectives. The project also gives the students experience with oral and written presentation. The project concludes during one class period at the end of the semester. Each group gives a short oral presentation describing their bridge, the division of labor within the group, and their design process. The presentation is followed by destructive testing of the group's bridge, using a small load frame and a digital readout load measurement device. Costs, benefits, and profits fore each group are calculated in real-time and displayed so that the winning entry can be announced immediately after the last bridge is broken.

An additional important objective of the bridge design project and course in general is that it the concepts and processes involved in projects within the discipline at the same time it helps integrate the freshman students into the larger Civil and Environmental Engineering undergraduate community. With respect to the project, this is done primarily by highlighting the project as a shared experience among present and past freshman within the department. The following characteristics of the project and/or the course intentionally address the communitybuilding objective of the course:

- The course is offered each semester and always includes the bridge design project.

- The project presentation/bridge breaking is a public event in which faculty and former students are invited to attend.

- The teaching assistants in the class are generally undergraduates who previously excelled in the course.

- At several points in the semester upperclassmen are invited to speak to the class about activities available to students in the department (e.g. student organizations, competitions, scholarship opportunities, social events, etc.)

- The design and performance characteristics for every current and previous entry in the design project are available to all students in the department on the department web page.

- The project is referred to as a design "competition," and all entries (present and past) are ranked according to the profit and prediction accuracy, using the rules for the current semester.

- The ASCE student chapter often uses the course's construction and testing equipment for its work on balsa wood bridge design competitions. 
Anecdotal evidence from discussions with students, instructor experience, and the written responses on the course evaluations suggest that the existing balsa wood design project has at least in part met the objectives described above. In addition we believe that the current design project provides students with useful experiences regarding engineering design. As mentioned earlier, we are now developing a new design project with an environmental, rather than structural design theme. In examining the current project we believe that there are several beneficial aspects that we would like to retain in our new environmental-themed design project. These features are as follows:

- A successful project requires care in both design and construction. Many promising designs have been failures because of shoddy construction.

- Public performance testing of each entry in the design contest provides an interesting and exciting experience for students and faculty.

- Parameters quantifying bridge costs and benefits can be modified from one semester to the next to lessen the possibility of student cheating.

- Students must recognize in their design that because of unavoidable uncertainty in aspect of the design and construction, actual performance is not exactly equal to expected performance. This uncertain performance must be accounted for during design.

- Test results from different semesters can be combined and provided to students thereby helping integrate new students into the community of existing students.

- Easy-to-use spreadsheet-based analysis software can be created that encourages students to analyze many candidate designs.

- Material costs for each project entry are reasonable $(<\$ 10)$.

- No special tools or skills are needed for construction.

Over 340 project entries have now been designed and constructed by student groups and ranked based on profit and prediction accuracy performance during 14 realizations of the bridge design project. An assessment of those entries in terms of the variability seen in the design and performance characteristics can be used to quantitatively analyze the extent to which the project objectives are met and desirable features realized. That assessment is provided in the following section.

\section{Analysis of Bridge Project Entries}

The project rules allow student groups quite a bit of flexibility in designing their bridge. All bridges must have a 24 -inch span, and must have a width and height within a range, and must have a measured mass less than 125 grams. Construction materials are limited to glue, cardboard for gusset plates, and $1 / 4$ " $\mathrm{x} 1 / 4$ " or $1 / 8$ " x $1 / 8$ " cross-section balsa wood sticks. One to four sticks may be glued together to give rectangular member cross-sections from $1 / 8 \times 1 / 8$ " up to $1 / 2$ " $\times 1 / 2$ " or $1 / 4 "$ x 1 ". Students are free to choose the location and number of nodes (joints), the number of cross-section sizes (referred to as a member type), the cross-section size for each member, and the size and design of gusset plates used to reinforce bridge joints.

Bridge designs within any given semester have been quite variable. For instance, while on average students have used approximately 200 inches of $1 / 4$ " $\mathrm{x} 1 / 4$ " in their bridge designs, the amount of wood used has varied widely, with more than 100 entries using less than 100 inches, and another 50 or so entries using more than 300 inches (Figure 2, top panel). Bridge strengths, which are measured with destructive testing and determine the benefit of the bridge, have also 
been highly variable (Figure 2, top panel). As a result of the variability in material costs and strengths, the calculated profits of the 342 entries are also highly variable (Figure 2, bottom panel). Interestingly both the amount of wood used and the bridge strength distributions look normal, while the bridge profit is more uniformly distributed and has a noticeably higher degree of variation (Figure 2).
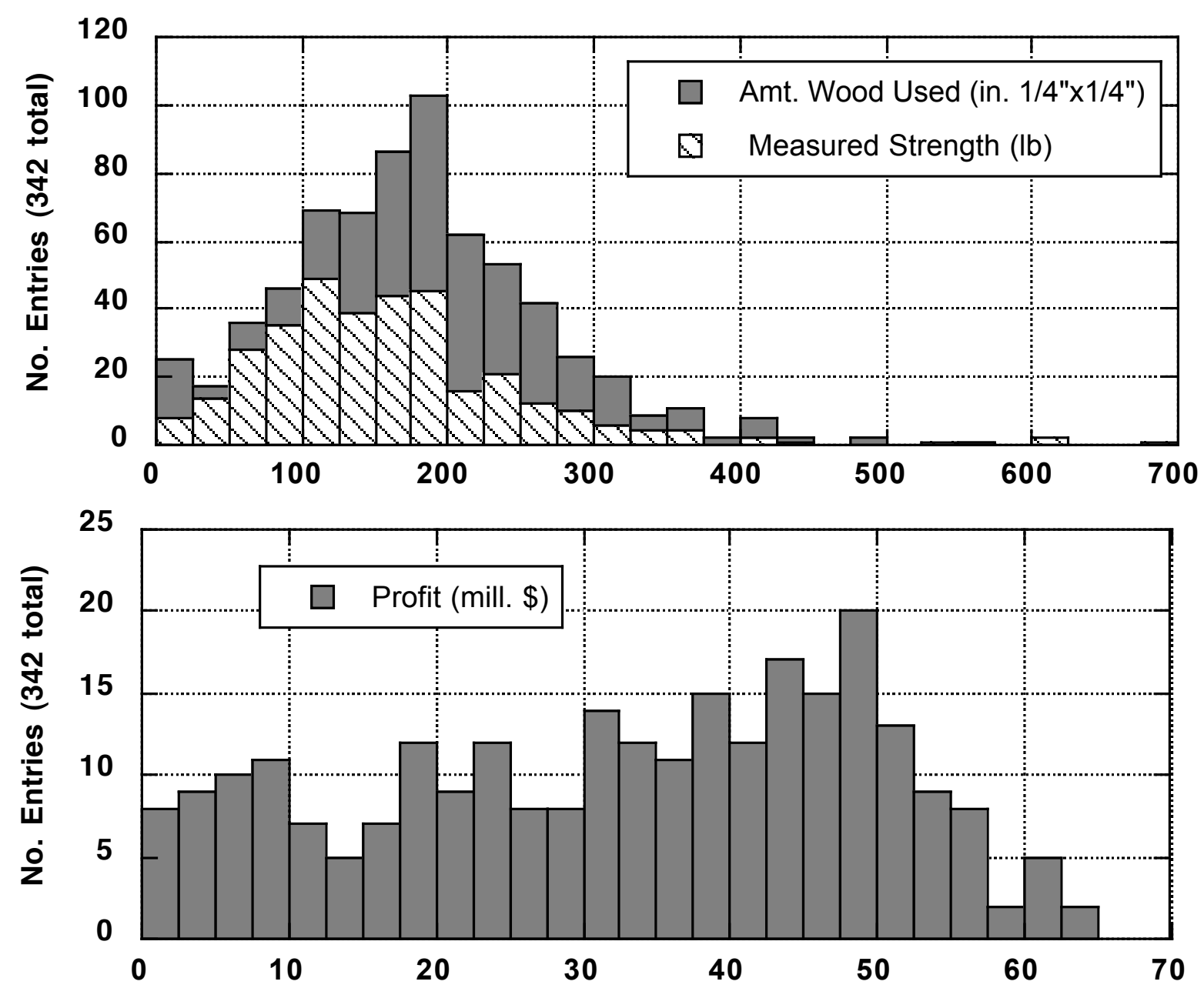

Figure 2. Histograms of the number of project entries (y-axis) for various amount of wood used and measured bridge strength (x-axis, upper panel) and bridge profit (x-axis, lower panel) for all 342 bridge project entries over 14 semesters since Spring 2002.

The histograms of the amount wood used, the bridge strength, and bridge profit are not able to reveal differences that exist from semester to semester. As mentioned earlier, in an effort to discourage sharing of the details of particular designs between current and former students, each semester a new set of parameters is used to quantify bridge costs and benefits. For instance in the spring semester, bridge benefits may plateau at strengths above 150 pounds, whereas the next semester it may take a bridge strength of 250 pounds to reach this same benefit level. Parameters describing costs (e.g. cost per node, per inch of wood, per gram of measured bridge mass) are also varied each semester). For this reason it is expected that the distribution of design characteristics will vary between the semesters. On the other hand, in changing the cost and 
benefit parameters each semester, it is desirable for purposes of ranking and grade assignment that the distributions of profit and prediction accuracy, which are used for grading, be constant.

To examine the variability in the designs and their performance, a one-way analysis of variance was performed on the 260 project entries from the nine spring semester classes (20022010). For this class (ENGR 1202), classes sizes and student preparation differs somewhat between spring and fall; the analysis is therefore restricted to just the spring semesters to eliminate these differences. Box plots of a key design characteristic (amount of $1 / 4$ " x 1/4" wood used) do show a significant variation between semesters (Figure 3, top panel). Bridge profit also varies from semester to semester, but to a lesser extent (Figure 3, bottom panel).
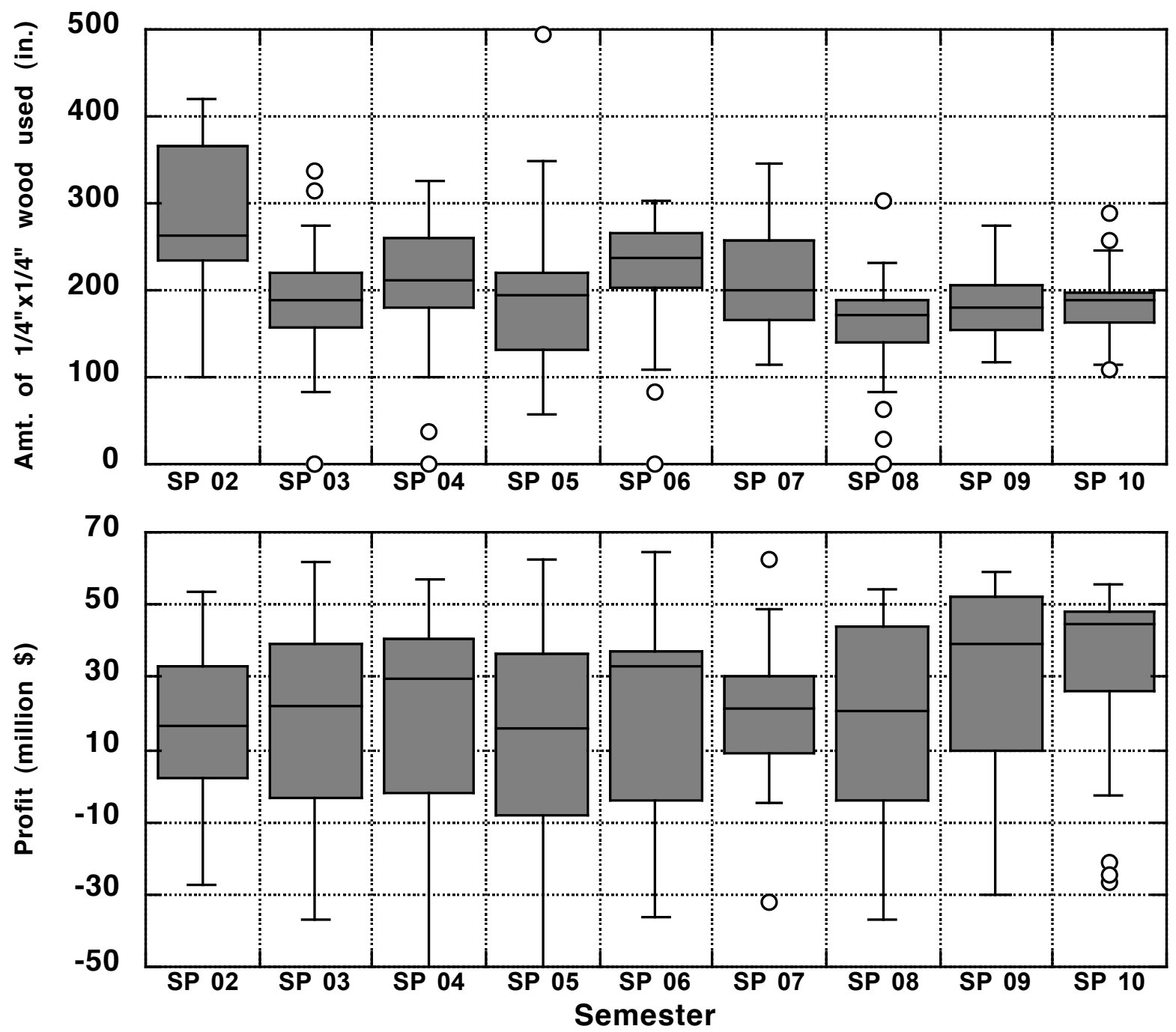

Figure 3. Distribution of the amount of wood used (top panel) and bridge profit (bottom panel) for individual bridges in each spring semester course. Boxes show the $25^{\text {th }}, 50^{\text {th }}$ and $75^{\text {th }}$ percentile values, while the bars give the $5^{\text {th }}$ and $95^{\text {th }}$ percentiles, and circles indicate outlying values.

The one-way analysis of variance was used to test the hypothesis that project measures did not vary from semester to semester. We expected that any of the measures related to bridge cost would vary in the project entries, since we had varied each semester the parameters describing 
costs and benefits with the objective of adding variability from semester to semester. For instance the relative cost of the two types of wood ( $1 / 4$ " $\times 1 / 4$ ", $1 / 8$ " $\times 1 / 8$ ") was changed to encourage differences in the designs from semester to semester. Using a one-way analysis of variance we tested eleven design and/or performance measures for between semester variation:

1. Number of nodes in bridge

2. Number of member types

3. Amount of $1 / 4 " \times 1 / 4$ " wood used

4. Amount of $1 / 8$ " x $1 / 8$ " wood used

5. Estimated bridge strength

6. Measured mass of bridge
7. $\quad$ Measured bridge strength

8. Bridge Cost

9. Bridge Benefit

10. Bridge Profit

11. Strength Prediction Penalty

Significant differences (at the 5\% significance level) were found for nine of the eleven measures (Table 1). The first nine measures relate directly to bridge design characteristics. Of these nine measures, only one (amount of $1 / 8$ " x 1/8" wood used) did not vary between semesters. This particular design measure seemed to be an outlier with regard to variability, as its coefficient of variation (201\%) greatly exceeded the other eight design measures (25\%-50\%). Interestingly the two measures involved in grading (profit, prediction inaccuracy penalty) had coefficients of variation that were nearly identical $(129 \%, 130 \%)$, and were much greater than the design measures (25\%-50\%). Bridge profit, the primary parameter used to assign grades and rank all of the entries across semesters, was found not to vary significantly from semester to semester. This was exactly the desired result. Each semester the cost and benefit parameters were changed with the intent of favoring a different set of entries from that of previous semesters. As a result bridge design measures varied from semester to semester, but the overarching numerical objective, to design a profitable bridge, remained unchanged between the semesters.

Table 1. One-way ANOVA results comparing between semester vs. within semester variances

\begin{tabular}{|c|l|c|c|c|c|}
\hline No. & \multicolumn{1}{|c|}{ Measure } & $\begin{array}{c}\text { Within vs. Between } \\
\text { Semester, } \\
\text { statistic }\end{array}$ & P-value & $\begin{array}{c}\text { Semester Means } \\
\text { Significantly } \\
\text { Different? (alpha } \\
=\mathbf{0 . 0 5} \text { ) }\end{array}$ & $\begin{array}{c}\text { Within } \\
\text { Semester } \\
\text { Coefficient of } \\
\text { Variation (\%) }\end{array}$ \\
\hline 1 & Number of Nodes & 3.29 & $1.38 \mathrm{E}-03$ & yes & $43 \%$ \\
\hline 2 & $\begin{array}{l}\text { Number of Member } \\
\text { Types }\end{array}$ & 2.21 & $2.71 \mathrm{E}-02$ & yes & $44 \%$ \\
\hline 3 & Estimated Strength & 6.69 & $6.12 \mathrm{E}-08$ & yes & $50 \%$ \\
\hline 4 & Amt. of 1/8" x 1/8" wood & 1.92 & $5.75 \mathrm{E}-02$ & no & $201 \%$ \\
\hline 5 & Amt. of 1/4" x 1/4" wood & 6.01 & $4.55 \mathrm{E}-07$ & yes & $36 \%$ \\
\hline 6 & Mass of Bridge & 6.26 & $2.16 \mathrm{E}-07$ & yes & $29 \%$ \\
\hline 7 & Measured Strength & 2.68 & $7.73 \mathrm{E}-03$ & yes & $58 \%$ \\
\hline 8 & Bridge Cost & 6.12 & $3.29 \mathrm{E}-07$ & yes & $25 \%$ \\
\hline 9 & Bridge Benefit & 2.10 & $3.59 \mathrm{E}-02$ & yes & $39 \%$ \\
\hline 10 & Bridge Profit & 1.72 & $9.35 \mathrm{E}-02$ & no & $\mathbf{1 2 9 \%}$ \\
\hline 11 & $\begin{array}{l}\text { Prediction Inaccuracy } \\
\text { Penalty }\end{array}$ & 6.41 & $1.39 \mathrm{E}-07$ & yes & $130 \%$ \\
\hline
\end{tabular}




\section{Assessment of Computer Programming Learning Outcomes}

An important component of the current course is that it gives students instruction on computer programming. In our current curricula this course is the only required course within the major that includes a significant portion of course content on computer programming. As part of the ongoing individual course assessment process (ICAP) that is undertaken each semester in this course, we have assessed our students' performance in achieving learning objectives related to computer programming. The assessment is performed once during the semester, usually as part of either a quiz or test taken near the end of the semester. Students are typically asked to write a short $(<10$ lines) piece of computer code (either Matlab or VBA) to perform a simple task. The question often requires them to write code with a simple branching (if-then-else) or looping (for, while, do) structure in their answer. While the questions vary slightly from semester to semester, each question is written to require only the basic programming knowledge that would be expected of the large majority (at least $85 \%$ ) of the students. An assessment of the last nine Spring semesters of the course (Figure 4) shows that students in the course generally do not meet the target objective. There is an upward trend, however, in the percent of students meeting the learning objective that is statistically significant (95\% significance level). As part of the ICAP process, we have made a number of changes in the timing, extent, and overall approach of the computer programming portion of the course, including a switch from Matlab to VBA, but as of yet, not enough students achieve the computer programming learning objective (Figure 4 ) of the course.

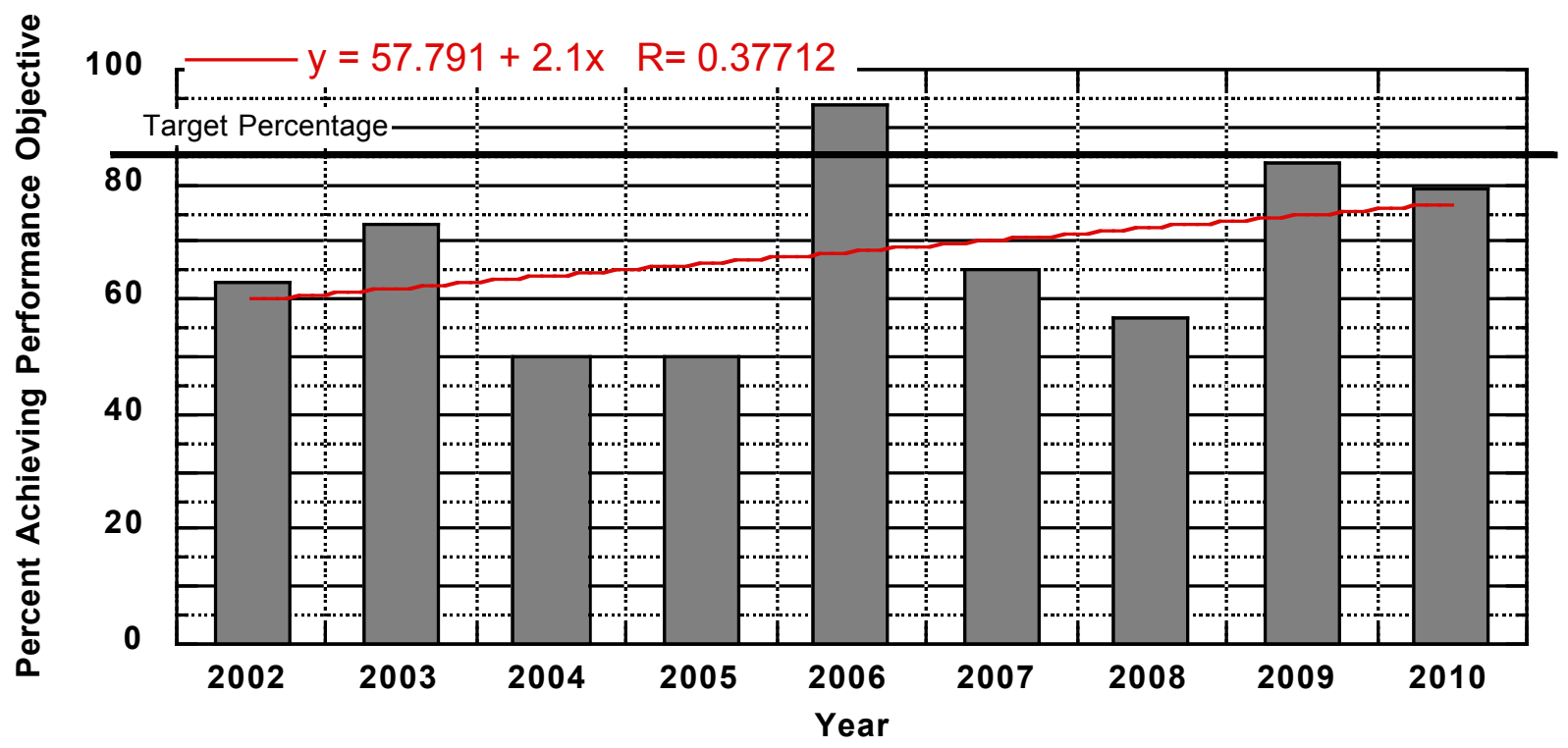

Figure 4. Percent of Students Achieving the Computer Programming Learning Objective, Spring Semesters, 2002-2010.

\section{The New Environmental-Themed Design Project}

The new environmental-themed project will ask groups of students to design and test a flocculation/sedimentation basin. Like the current project it will retain the objective of using 
attached learning $^{7}$ that connects content (e.g. engineering analysis, computer programming) to a practical hands-on project. Two engineering analysis concepts will be introduced during the semester. First we will present the Stokes settling equations ${ }^{12}$ as an example of static equilibrium, in which the settling velocity of a particle is determined by balancing drag, buoyancy, and gravitational forces. Stokes settling equations will be used to motivate course content on coagulation, whereby an introduced coagulant (ferric chloride) accelerates particle growth and thereby increases particle fall velocity by larger particles. Finally the concept of a mass balance will be used to develop equations for the suspended sediment concentration in the effluent of a sedimentation tank based upon the flow through the tank, the size of the tank (length, width, height), and the fall velocities of particles within different size ranges. These engineering analysis concepts will be used to develop a spreadsheet analysis system that will allow students to investigate how changes in each of the design parameters and the characteristics of the influent will affect performance of a candidate design.

We believe that many of the desirable characteristics of the existing project can be retained in the new project. We will retain the notion of trading off costs and benefits of candidate designs. We believe it is this project feature that provides for a variety of high performing designs. We will also retain the in-class testing and immediate design evaluation characteristics of the current project. Costs will be determined as a function of the amount of coagulant used (increases particle size and thus fall velocity) and the size of the basin (increases retention time). Benefits will be determined using the same sort of "S-shaped" function currently used, but in this case effluent turbidity will be the independent variable used to calculate benefit. Benefits will decrease as the measured effluent turbidity increases. The sedimentation "basins" will actually be identical, reusable, inexpensive plastic flasks that will be provided to each group. The samples to be treated in the students' basins will be made up with water and kaolinite clay of a known concentration. Students will "buy" doses of coagulant that will include additional compounds for $\mathrm{pH}$ stabilization. The size of the coagulant dose will vary according to the characteristics of each design entry. Once the coagulant is added and mixed, the "basins" will be allowed to quiescently settle the suspended sediments. The settling times will vary according to the design strategy of each group (larger basins will have longer settling times). The parameters used to quantify costs and benefits will be set to provide for a range of suitable designs. For instance a small basin with a large coagulant dose might perform equally well to a large basin with a small coagulant dose. The range of settling times will be set so that the testing of each design can be accomplished within a class period. Testing will involve sampling each basin and measuring turbidity. Based upon the measured turbidity, the coagulant dose, and the basin size, design entries will earn a project profit. A spreadsheet will be used to summarize the results of the in-class testing once all the measurements are taken.

\section{Summary and Conclusions}

Our second semester freshmen engineering course has since 2002 included design, engineering analysis, and computer programming components. The culminating design project attaches the engineering analysis and programming to a hands-on, real-world design project. Based on our experience and assessment, the existing project has many desirable characteristics. Beginning in the current semester, we will offer an alternative design experience (design of a coagulation/sedimentation basin) that will hopefully retain many of the desirable features of the existing project while providing course content closer to the interests of environmental 
engineers. This new project will, as we have done in the past, will attach engineering analysis and computer programming to a hands-on design project. Using the results of our ongoing course assessment, we will continue to develop the computer programming portion of the course so that students achieve the learning objective. As with the current project, we plan to use assessment of student designs in the future to evaluate the performance of this new project as an element within our freshman engineering course.

Bibliography

1. Shelnutt, W., Allen, M., Badami, V., Buch, K., et al. 1998. A Multidisciplinary Course Sequence Stressing Team Skills, Conceptual Design, Creative Problem Solving, Professional Practice, and Computing Skills for Students Entering the William States Lee College of Engineering. Proceedings of the 1998 American Society for Engineering Education. Washington, D.C.: American Society for Engineering Education.

2. Gardner, J.F., Ackler, H.D., Paris, A.J, and Moll, A.J. 2002. Rethinking First Year Engineering at Boise State: Assessment and Improvement. Proceedings of the 2002 American Society for Engineering Education. Washington, D.C.: American Society for Engineering Education.

3. Sorby, S.A., Monte, A.E., and Hein, G.L. 2001. Implementing a Common First Year Engineering Program at Michigan Tech. Proceedings of the 2001 American Society for Engineering Education. Washington, D.C.: American Society for Engineering Education.

4. MATLAB, MATrix LABoratory is a trademark of The Mathworks, Inc., Natick Massachusetts.

5. Bowen, J.D. 2003. Using a Hands-On, Project-Based Approach to Introduce Civil Engineering to Freshmen. Proceedings of the 2003 American Society for Engineering Education. Washington, D.C.: American Society for Engineering Education

6. Bowen, J.D. 2003. An Automated Grading System for Teaching MATLAB to Freshman Engineers. Proceedings of the 2003 American Society for Engineering Education. Washington, D.C.: American Society for Engineering Education.

7. Yokomoto, C. F., Rizkalla, M. E., O’Loughlin, C. L., El-Sharkawy M. A., Lamm, N. P., 1999. Developing a Motivational Freshman Course in Using the Principle of Attached Learning," Journal of Engineering Education, 88, 99-106 (Jan. 1999).

8. Sheppard, S., and Jenison, R. 1996. Thoughts on Freshman Engineering Design Experiences. Proceedings, Annual Frontiers in Education Conference. ASEE/IEEE, Salt Lake City 1996, pp. 909913.

9. Sheppard, S., and Jenison, R. 1997. Examples of Freshman Design Education. Int. J. Engineering Ed., Vol. 13, No. 4, p. 248-261.

10. Reisslein, M, Tylavsky, D., Matar, B., Seeling, P., and J. Reisslein, 2007. Active and Cooperative learning in a freshman digital design course: Impact on persistence in engineering and student motivation orientation, Proceedings of the ASEE/IEEE Frontiers in Education, pp. S4A-1 - S4A-6.

11. Thompson, M. K. 2009. ED100: Shifting Paradigms in Design Education and Student Thinking at KAIST. In Proceedings of the 2009 CIRP Design Conference.

12. Clark, M. M. 2009. Transport modeling for environmental engineers and scientists. John Wiley \& Sons, New York, 629 p. 